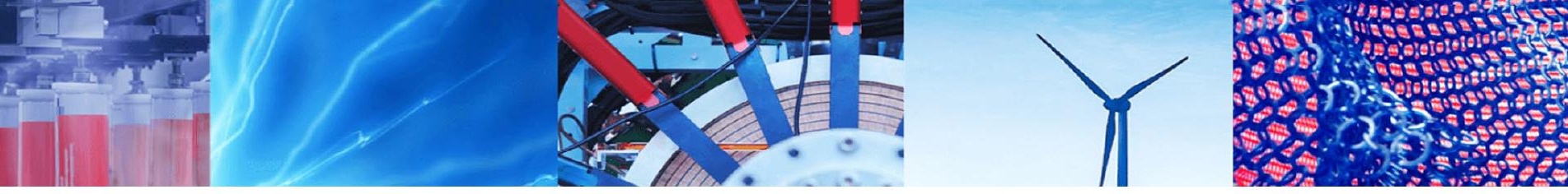

Research Article

\title{
Rambutan peel derived porous carbons for lithium sulfur battery
}

\author{
Arenst Andreas Arie ${ }^{1}\left[\right.$ [D Hans Kristianto ${ }^{1} \cdot$ Ratna Frida Susanti $^{1} \cdot$ Joong Kee Lee ${ }^{2}$
}

Received: 6 August 2020 / Accepted: 29 March 2021 / Published online: 7 April 2021

(c) The Author(s) $2021 \quad$ OPEN

\begin{abstract}
Porous carbons were prepared from the biomass waste rambutan peels using hydrothermal carbonization followed by the $\mathrm{KOH}$ activation process. Rambutan peel derived porous carbons (RPC) with high surface area of $2104 \mathrm{~m}^{2} \mathrm{~g}^{-1}$ and large pore volume of $1.2 \mathrm{~cm}^{3} \mathrm{~g}^{-1}$ were obtained at $\mathrm{KOH} /$ carbon ratio of 4 and activation temperature of $900^{\circ} \mathrm{C}$. The asobtained porous carbons were capable of encapsulating sulfur with a high loading of $68.2 \mathrm{wt} \%$ to form RPC/S composite cathode for lithium sulfur (Li-S) battery. High specific discharge capacities of about $1275 \mathrm{mAh} \mathrm{g}^{-1}$ were demonstrated by the RPC/S composites at $0.1 \mathrm{C}$. After 200 cycles at $0.1 \mathrm{C}$, a high specific capacity of $936 \mathrm{mAh} \mathrm{g}^{-1}$ was maintained, showing an excellent capacity retention of about $73 \%$.
\end{abstract}

Keywords Biomass $\cdot$ Porous Carbon $\cdot$ Rambutan peel $\cdot$ Cathode $\cdot$ Li-S Battery

\section{Introduction}

To support the development of renewable energy and reduce the $\mathrm{CO}_{2}$ emissions, the role of electrochemical energy storage especially rechargeable battery is crucially required [1]. Lithium sulfur ( $\mathrm{Li}-\mathrm{S})$ battery is one of the candidates to be developed as promising battery system due to the high energy density of $2500 \mathrm{Wh} \mathrm{kg}^{-1}$, abundant raw material and safety issues $[2,3]$. However, there are some obstacles that should be handled well for further commercial and practical use of this battery system [4]. The specific issues are due to the low conductivity of sulfur and its alloying products with $\mathrm{Li}\left(\mathrm{Li}_{2} \mathrm{~S}_{\mathrm{x}}\right)$, high solubility of intermediates polysulfide $\left(\mathrm{Li}_{2} \mathrm{~S}_{x^{\prime}} 4 \leq \mathrm{x} \leq 8\right)$, enormous volume expansion during cycling of sulfur electrodes and serious shuttle effects [5-8]. All of these issues will cause poor electrochemical performance of sulfur cathodes in $\mathrm{Li}-\mathrm{S}$ battery because of the rapid capacity loss and high irreversible capacity [9]. Hence, it is urgent to solve those problems, so more reliable Li-S battery system can be used for commercial applications.
The above mentioned problems can be effectively handled by using porous carbons as composite along with sulfur [10-12]. The presence of porous carbons may enhance the electrical conductivity of sulfur cathodes as well as their connecting pores can act as polysulfide reservoirs [13-15]. It can minimize the effect of polysulfide shuttle during cycle test of the composite electrodes. For production of the porous carbons, biomass can become one candidate of the most possible precursors because it is cheap, high abundant, renewable, green and unique porous structures [16-24]. Various of biomass has been used as carbons precursors for for Li-S battery system such as avocado shells [25], snake-skin fruit peel[26], hickory shell [27], rapeseed meal [28], moss [29], dandelion [30], banana peel [31], fiber of fern [32], wheat straw [33], mangosteen peel [34], xanthoceras sorbifolia husks [35], goat hair [36], rice husks [37], pistachio shell [38], almond shell [39], waste mandarin peels [17], waste tea [40] and many others [41].

Rambutan (Nephelium lappaceum $L$ ) is a popular tropical fruit that belongs to Sapindaceae family [42]. Indonesia

$\triangle$ Arenst Andreas Arie, arenst@unpar.ac.id; arenst@yahoo.com | ${ }^{1}$ Department of Chemical Engineering, Faculty of Industrial Technology, Parahyangan Catholic University, Ciumbuleuit 94, Bandung 40141, Indonesia. ${ }^{2}$ Advanced Materials Energy Processing Laboratory, Center of Energy Convergence, Korea Institute of Science and Technology, Seoul, Republic of Korea. 
produces many varieties of rambutan, there are more than 20 varieties can be found. Fruits are oval-shaped with the peel is green, yellow or red when ripe. Normally, after consuming the rambutan fruit, the peel is regarded as waste and disposal of it can cause environmental problem in the community. Therefore, conversion of rambutan peel into useful product such as porous carbons in $\mathrm{Li}-\mathrm{S}$ batteries, is expected can reduce the processing cost of the peel waste. The main merit of using rambutan peel as raw materials for production of porous carbons is the huge abundant resources of it which can minimize the production cost of $\mathrm{Li}-\mathrm{S}$ batteries.

In this work, rambutan peels were utilized to prepare porous carbons to encapsulate sulfur as cathodes for lithium sulfur battery. Porous carbons were initially synthesized by hydrothermal treatment of waste rambutan peel followed by the $\mathrm{KOH}$ chemical activation process by varying the impregnation ratio between $\mathrm{KOH}$ and the precursors. The pretreatment of hydrothermal converts rambutan peel into a solid intermediate product (hydro-char) at relatively low temperature $\left(180-250^{\circ} \mathrm{C}\right)$ and saturated pressure (2-10 MPa). The hydro-char has better physicochemical characteristics than its carbon precursors [43]. The role of the next step of chemical activation is develop carbon materials with high surface area and porosity. In specific, the effect of impregnation ratio on the electrochemical performance of porous carbon-sulfur composite cathodes will be studied.

\section{Experimental}

\subsection{Preparation process of porous carbons}

The preparation process of rambutan peel based porous carbons was done by hydrothermal carbonization and then followed by the chemical activation process using $\mathrm{KOH}$. The rambutan peel was collected from the local market in Cimahi, Indonesia. After grounded by mortar and pestle pestle, the peel powders were screened by sieve screening to have uniform particle size distribution. After screening, the peel powder was dispersed in distilled water and then was loaded into a Teflon-lined stainless steel autoclave and hydrothermally treated at $200{ }^{\circ} \mathrm{C}$ for $20 \mathrm{~h}$. After the reaction completed, the autoclave was cooled down into room temperature. The resulting solid carbons was separated by centrifuge and then washed with ethanol and distilled several times. The washed solids were then dried in an oven at $80^{\circ} \mathrm{C}$ overnight. The dried hydrochar was then separately mixed with $\mathrm{KOH}$, respectively with different impregnation ratio of 1:1, 1:2 and 1:4 (mass ratio between of tea powder and $\mathrm{KOH}$ ). Finally, further pyrolysis carbonization was applied to the impegnated hydrochar samples at temperature of $900^{\circ} \mathrm{C}$ for $2 \mathrm{~h}$ with heating rate of $5^{\circ} \mathrm{C} / \mathrm{min}$ in $\mathrm{N}_{2}$ atmosphere. The resulting solid carbon was washed with $1 \mathrm{M} \mathrm{HCl}$ solution and distilled water several times until the filtrate became neutral in $\mathrm{pH}$. The obtained wet carbon was finally dried at $80^{\circ} \mathrm{C}$ overnight. The carbon samples were denoted as RPC- 1 which was obtained by impregnation ratio of $1: 1$, RPC-2 for impregnation ratio of 1:2 and RPC- 4 for impregnation ratio of 1:4.

\subsection{Preparation process of porous carbon-sulfur composites}

The porous carbon-sulfur composites were prepared by a standard melt-diffusion method. 3 samples of porous carbons (RPC-1, RPC-2 and RPC-4) and elemental sulfur (Sigma Aldrich) were mixed with the weight ratio of 1:3 by using pestle and mortar followed by heating under vacuum at $155^{\circ} \mathrm{C}$ for $10 \mathrm{~h}$ in a crucible to produce carbon-sulfur composites. The choice of this temperature because it is slightly above the melting point of sulfur, where solid orthorhombic $\mathrm{a}-\mathrm{S}$ melts into liquid cyclic $\mathrm{a}-\mathrm{S} 8$ and its viscosity is the lowest. The melted sulfur infiltrates into the pore structures of the carbon by capillary forces [44]. The carbon-sulfur composites were denoted as RPC/S-1, RPC/S-2 and RPC/S-4.

\subsection{Structural characterizations}

The textural, structural and morphological properties of rambutan peel porous carbon (RPC) and their corresponding sulfur composites (RPC/S) were investigated by scanning electron microscope (SEM, HITACHI), energy dispersive X-ray spectroscopy (EDXS) and X-ray diffraction (XRD, Bruker). The $\mathrm{N}_{2}$ adsorption-desorption isotherm was obtained by surface area analyzer (Micromeritics). Pore size distributions were estimated using density functional theory (DFT) for micropores and the Barrett-JoynerHalenda (BJH) model for mesopores. Thermogravimetric analysis was conducted to measure the sulfur content in the composites.

\subsection{Electrochemical characterizations}

The electrochemical performance of composite electrodes was investigated by coin cells fabricated in an Arfilled glove box. The used electrolyte was $1 \mathrm{M} \mathrm{LiN}\left(\mathrm{CF}_{3} \mathrm{SO}_{2}\right)_{2}$ (LiTFSI) dissolved in a mixture of 1,3-dioxolane (DOL)/ dimethoxyethane (DME) (1:1 volume ratio) containing $0.1 \mathrm{M} \mathrm{LiNO}_{3}$ and Li metal was used as reference/counter electrode. Electrode containing RPC/S, Super P conducting carbon and poly(vinylidene fluoride) (PVDF) binder were made by casting slurry onto Al foil, in the weight of 
$80: 10: 10$. The ratio of electrolyte/sulfur composite ratio was set about $40 \mu \mathrm{L} / \mathrm{mg}$. The typical mass loading of sulfur in the electrode was $1.1 \mathrm{mg} \mathrm{cm}^{-2}$. Charge-discharge measurements were conducted on battery tester (MACCOR) at $1.5-30.0 \mathrm{~V}$ vs. $\mathrm{Li}^{-} \mathrm{Li}^{+}$.

\section{Results and discussion}

The structure of rambutan peel-based carbon (RHC) was then investigated by X-ray diffraction (XRD), as seen in Fig. 1. Two broad peaks are identified at around $23^{\circ}$ and $23^{\circ}$ for all RHC samples. This suggests that the RHC samples possess are turbostratic carbon structures. After mixing with sulfur, no apparent XRD peak for elemental sulfur can be found in RPC/S composite, suggesting that the sulfur into carbon pores has been infiltrated well into the carbon pores. The lack of crystallinity of the sulfur in its composites (XRD pattern) implies that sulfur exists in a highly dispersed state inside the pores of carbon [45].

The structure of RPC and RPC/S samples was also studied by using Raman spectroscopy, as shown by Fig. 2, where two distinctive peaks can be seen namely the defect-induced $D$ peak at around $1327 \mathrm{~cm}^{-1}$ and crystalline graphite $G$ peak located at $1594 \mathrm{~cm}^{-1}$. The intensity ratio of $D$ and $G$ peaks $\left(I_{D} / I_{G}\right)$ can be also estimated. The relative intensity (ID/IG) of RPC-1, RPC-2 and RPC-4 can be estimated about 1.12, 1.13 and 1.15 , respectively. It seemed that the degree of disordered carbon structure has increased by increasing the impregnation ratio from 1:1 to $1: 4$ in the carbon preparation process. After impregnating with sulfur, the relative intensity of RPC/S-1, RPC/S-2 and $\mathrm{RPC} / \mathrm{S}-4$ is about 1.19,1.27 and 1.33, respectively. It can be

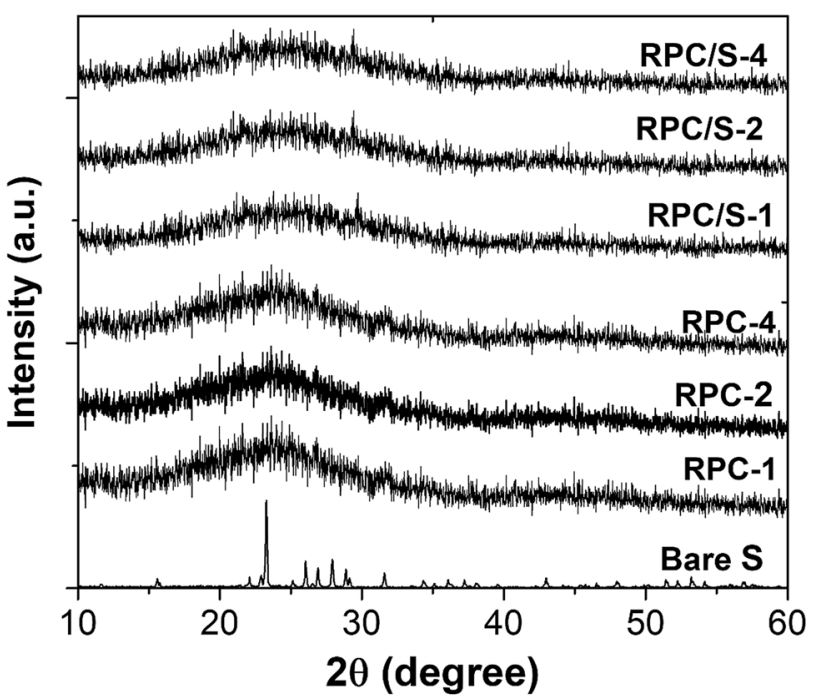

Fig. 1 XRD patterns of RPC and RPC/S samples

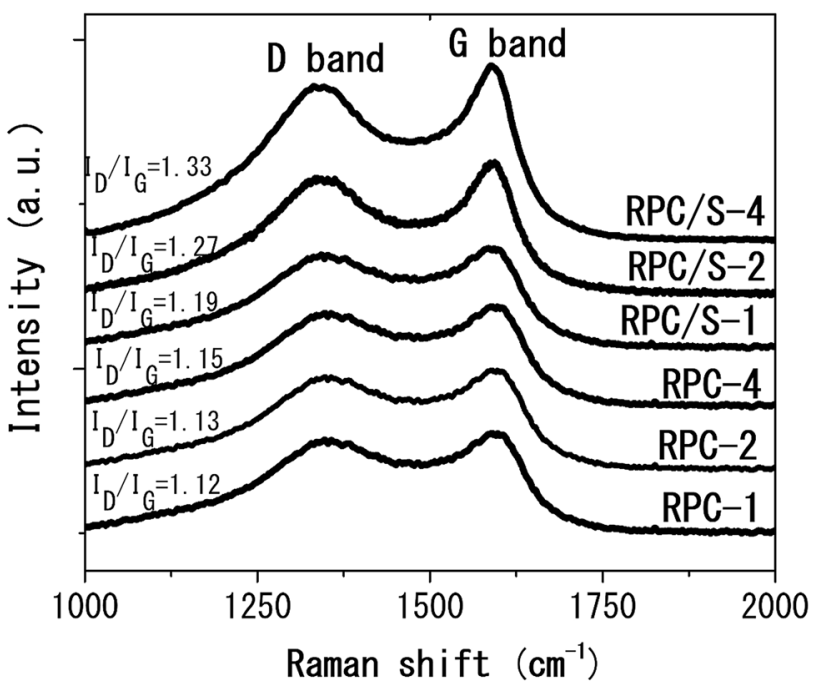

Fig. 2 Raman spectra of RPC and RPC/S samples

said that the degree of disordered structure is increased by impregnating carbons with sulfur. Furthermore, we did not find any possible signals in the range of $100-500 \mathrm{~cm}^{-1}$, caused by the presence of sulfur $[46,47]$.

The textural properties of RPC/S composites such as BET surface areas and pore size distribution were investigated by $\mathrm{N}_{2}$ adsorption-desorption experiments at $77 \mathrm{~K}$. We can see in Fig. 3 that the $\mathrm{N}_{2}$ adsorption desorption isotherms of RPC and its composites are similar in shape which can be categorized as type IV isotherm of IUPAC classification. The presence of microporous structure can be detected from the high adsorption amount in low relative pressure. The textural properties of all samples are shown in Table 1. The BET surface areas of the RPC-4, RPC- 2 and RPC- 1 are about 2104,1975 and $1527 \mathrm{~m}^{2} \mathrm{~g}^{-1}$, respectively. While the total pore volume of RPC-4, RPC- 2 and RPC- 1 are estimated as $1.2,1.07$ and $0.89 \mathrm{~cm}^{3} \mathrm{~g}^{-1}$ and their pore size distribution (Fig. 1d) suggest dominant mesopores. After mixing with sulfur, the surface area of RPC-4, RPC- 2 and RPC- 1 are decreasing to $40.7,35.2$ and $22.7 \mathrm{~m}^{2} \mathrm{~g}^{-1}$. and the total pore volume also decreases from $0.64,0.52$ and $0.41 \mathrm{~cm}^{3} \mathrm{~g}^{-1}$, showing the successful infiltration of sulfur into carbon matrix using melt-diffusion process.

Figure 4 shows the TGA measurements of RPC/S composites to estimate the exact sulfur content in an argon flow. As seen in Fig. 4, the content of sulfur in the RPC/S-1, RPC/S-2 and RPC/S- 4 composites was about 55.2, 61.9 and $68.2 \mathrm{wt} \%$.

Figure 5 presents the SEM images of the rambutan peel based porous carbons and their corresponding composites with sulfur. We can observe that no apparent aggregation of bulk sulfur on the surface of porous carbons, meaning that the sulfur has been infused perfectly into 

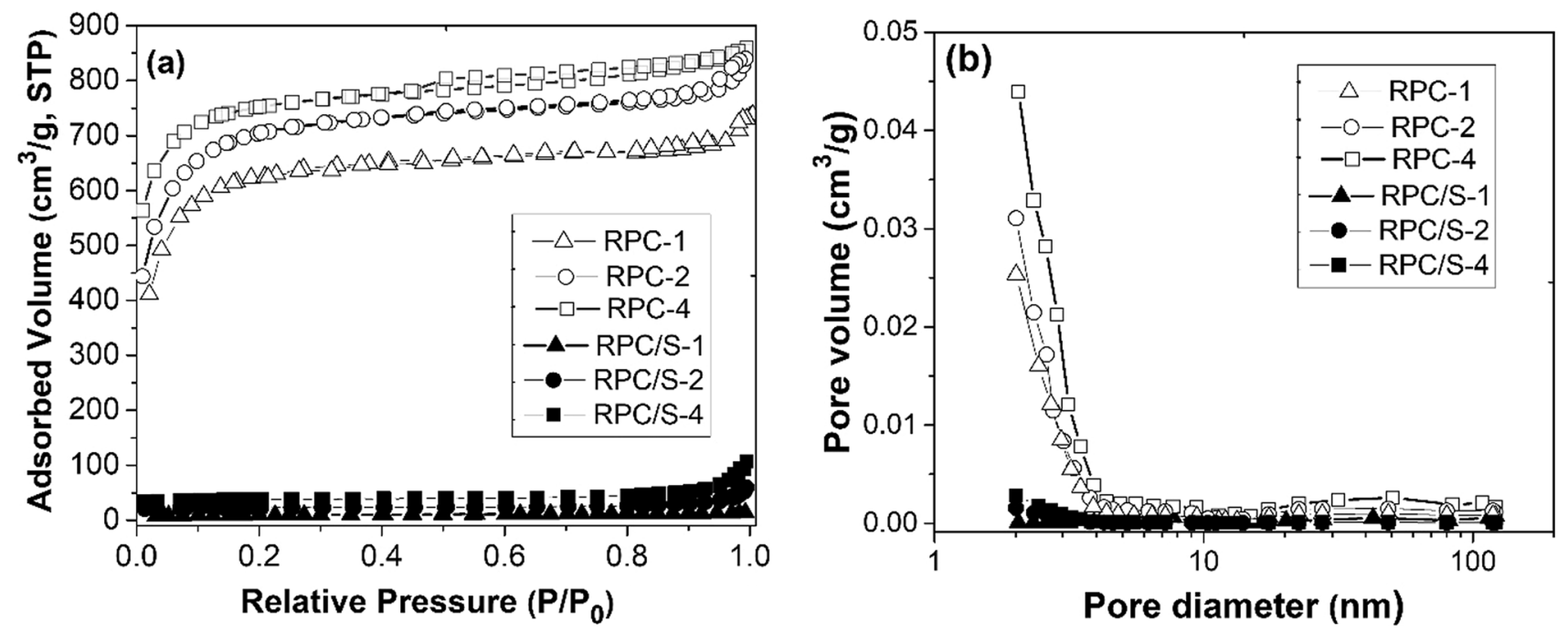

Fig. 3 a Nitrogen adsorption/desorption isotherms (measured at $77 \mathrm{~K}$ ) and $\mathbf{b}$ Cumulative pore size distribution (PSD) of the RPC and RPC/S samples

Table 1 Textural properties of rambutan peel derived porous carbons and their corresponding composites with sulfur

\begin{tabular}{llll}
\hline Sample & $\begin{array}{l}\text { BET Surface area } \\
\left(\mathrm{m}^{2} / \mathrm{g}\right)\end{array}$ & $\begin{array}{l}\text { Pore volume } \\
\left(\mathrm{cm}^{3} / \mathrm{g}\right)\end{array}$ & $\begin{array}{l}\text { Average pore } \\
\text { diameter }(\mathrm{nm})\end{array}$ \\
\hline RPC-1 & 1527 & 0.89 & 2.28 \\
$\mathrm{RPC}-2$ & 1975 & 1.07 & 2.15 \\
$\mathrm{RPC}-4$ & 2104 & 1.2 & 2.08 \\
$\mathrm{RPC} / \mathrm{S}-1$ & 22.7 & 0.41 & 6.7 \\
$\mathrm{RPC} / \mathrm{S}-2$ & 35.2 & 0.52 & 7.8 \\
$\mathrm{RPC} / \mathrm{S}-4$ & 40.7 & 0.64 & 8.3 \\
\hline
\end{tabular}

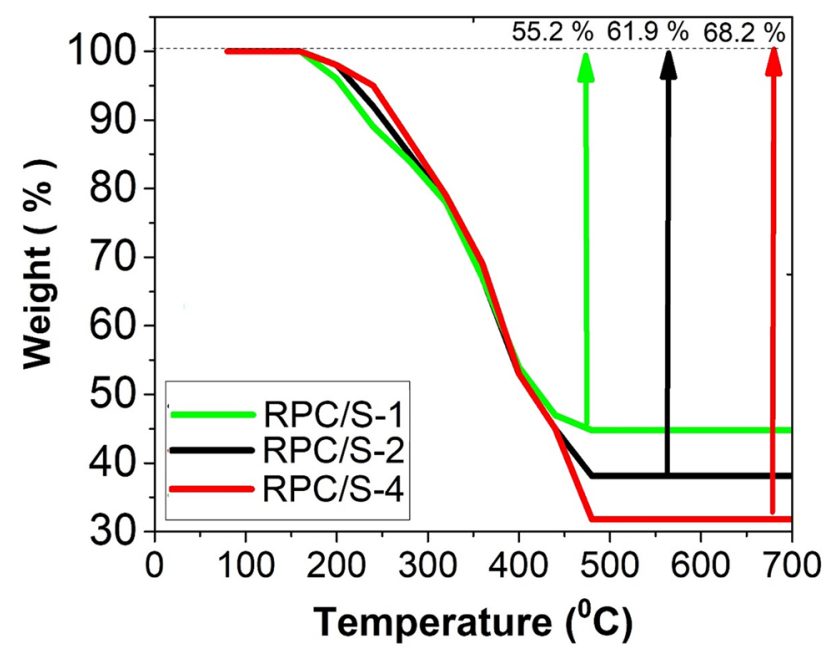

Fig. 4 TGA curves of sulfur composites of rambutan peel based porous carbons obtained at $900{ }^{\circ} \mathrm{C}$ with different impregnation ratios the pores of the carbons matrix. Table 2 shows the energy dispersive X-ray spectroscopy measurements of all carbon samples. It suggests that there are no contaminants found in the carbon samples.

The electrochemical performances of the RPC/S composite cathodes for LiS batteries were studied by coil cells. Figure 6a shows the comparison of cycle performance of all RPC/S composite cathodes at current density of $0.2 \mathrm{C}$ between 1.5 and $3.0 \mathrm{~V} \mathrm{vs} \mathrm{Li/Li+}$ in which the specific capacity of LiS cells were determined using the sulfur mass. All the samples show almost the same trend where all the capacities are decaying in the first 10 cycles and starting to have a stable cycle performance until 100th cycle. The $\mathrm{RPC} / \mathrm{S}-4$ sample demonstrated the most superior performance among others until 100 cycles of charge/discharge of LiS cells. The initial specific discharge capacity of RPC/S-4 samples is $1275 \mathrm{mAh} \mathrm{g}^{-1}$ and the capacity is remaining at $944 \mathrm{mAh} \mathrm{g}^{-1}$ at the end of 100th cycle. While for the RPC/S-2 and RPC/S-1 samples, they showed more inferior performance in which their initial capacities are about 1100 and $910 \mathrm{mAh} \mathrm{g}^{-1}$ and their final capacities at 100th cycle are around 824 and $657 \mathrm{mAh} \mathrm{g}^{-1}$, respectively. The superior performance of RPC/S-4 is attributed to the highest BET surface area which can allow more sulfur to be encapsulated in the porous carbon matrix of RPC/S-4. In addition, the large pore volume of RPC/S-4 can accommodate the volume expansion occurred during the cycles of LiS cells.

Figure $6 \mathrm{~b}$ shows the long cycle test of RPC/S- 4 sample measured at current density of $0.2 \mathrm{C}$ between 1.5 and $3.0 \mathrm{~V}$ $\mathrm{vs} \mathrm{Li} / \mathrm{Li}^{+}$. It can be seen that the capacity at end of 200th cycle is about $936 \mathrm{mAh} \mathrm{g}^{-1}$, reflecting a capacity retention 

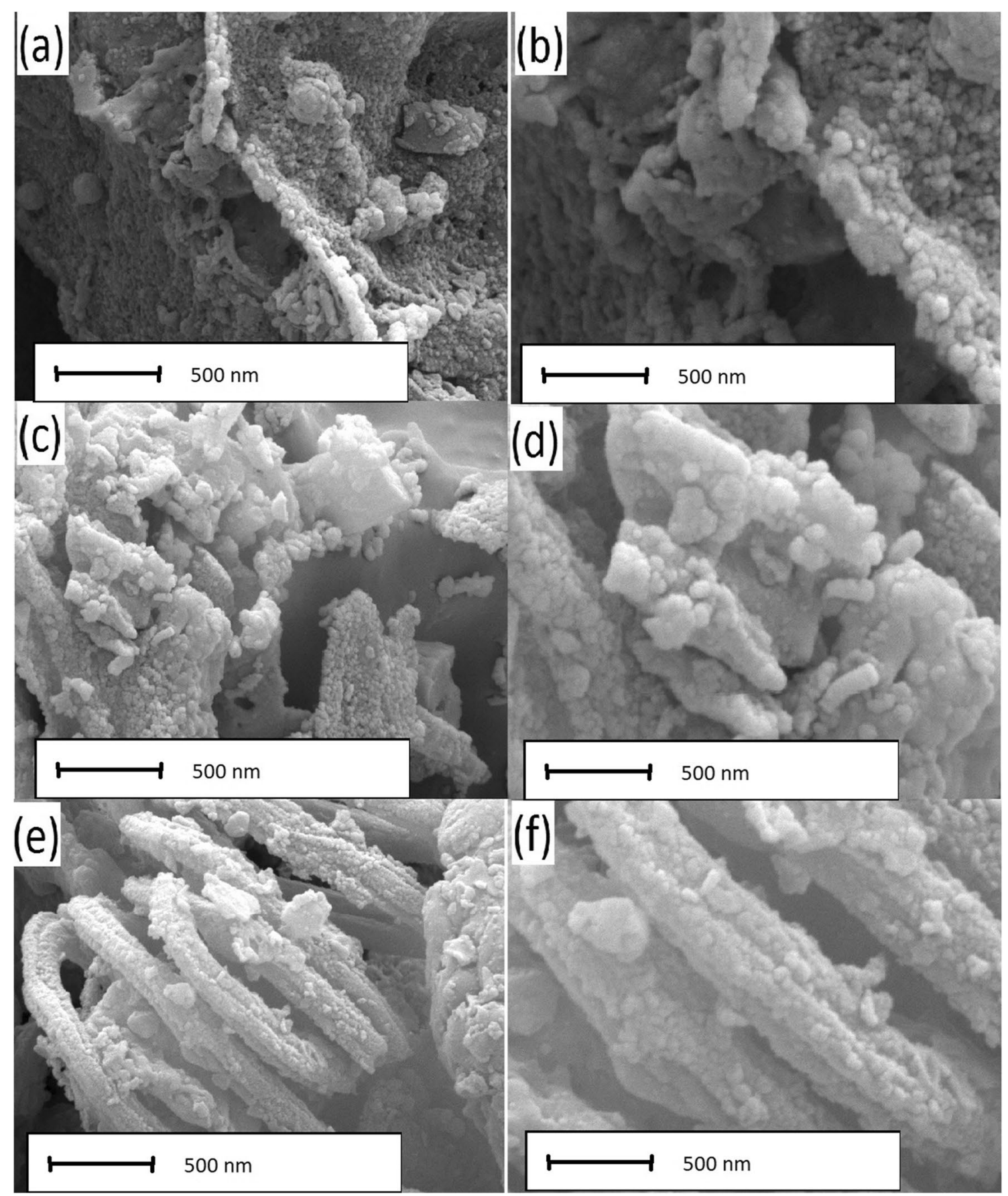

Fig. 5 SEM images of a RPC-1, b RPC/S-1, c RPC-2, d RPC/S-2, e RPC-4 and f RPC/S-4

Table 2 EDX analysis of RPC samples

\begin{tabular}{llll}
\hline Samples & Carbon (wt\%) & Oxygen (wt\%) & Nitrogen (wt\%) \\
\hline RPC-1 & 92.08 & 7.21 & 0.71 \\
RPC-2 & 91.87 & 7.87 & 0.26 \\
RPC-4 & 92.53 & 7.16 & 0.31 \\
\hline
\end{tabular}

of $73 \%$. The columbic efficiency is about $89 \%$ in the first cycle and it is increasing in the subsequent cycles at about $99 \%$. This excellent long cycle performance is also due to the high surface area and large pore volume of porous carbons derived from the rambutan peel obtained by the impregnation ratio of 4 .

Figure $6 c$ then shows the voltage profiles of RPC/S-4 sample at the 1st, 10th, 50th, 100th and 200th cycle. For 

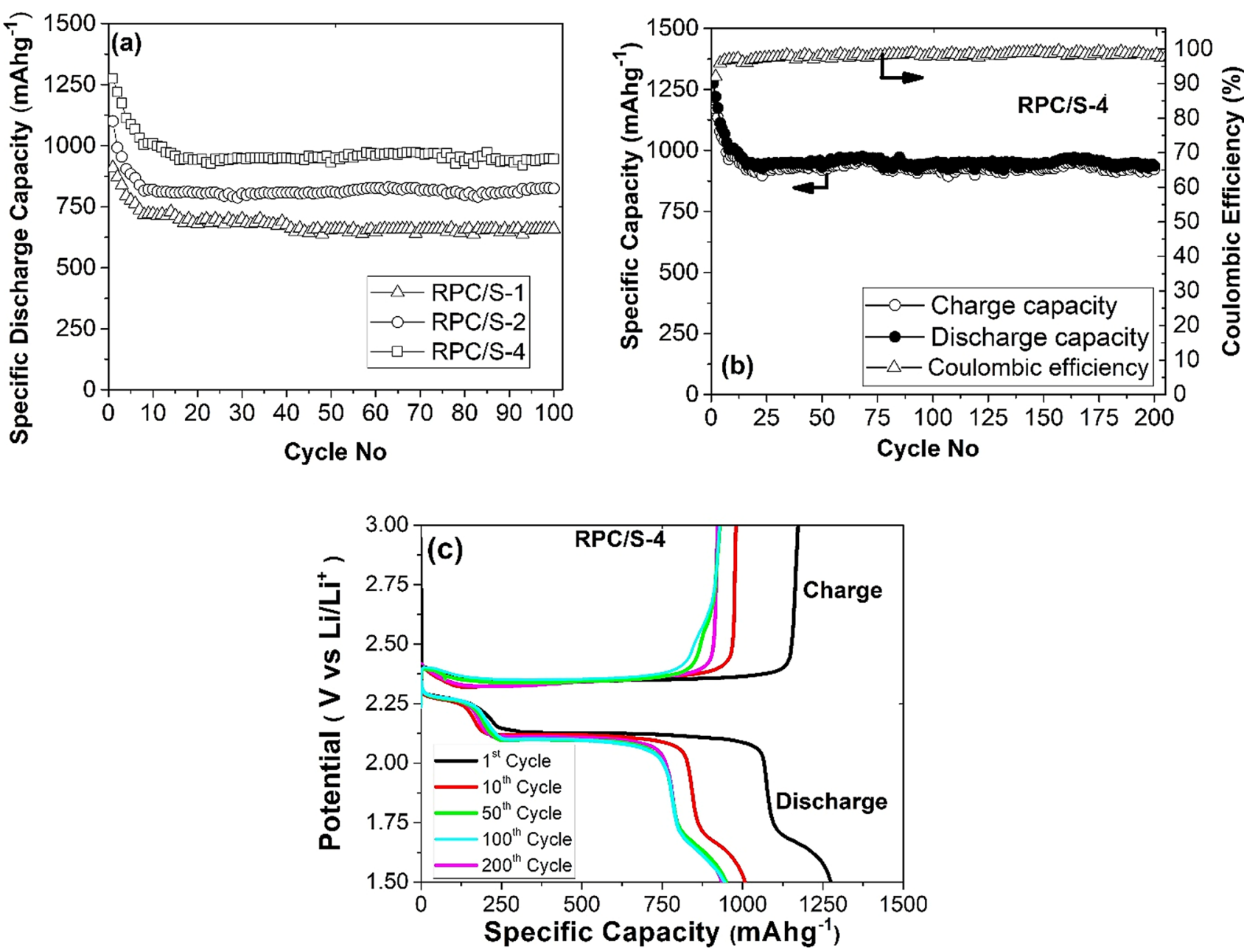

Fig. 6 a Comparison of cycle performance of all carbon-sulfur composites, b long cycle performance of RPC/S-4 and c galvanostatic charge-discharge profiles of RPC/S-4, measured at current density of $0.2 \mathrm{C}$ and cut-off voltage between 1.5 and $3.0 \mathrm{~V} \mathrm{vs} \mathrm{Li} / \mathrm{Li}^{+}$

all cycles, we can observe that there are two voltage discharge plateaus and one voltage charge plateau at $2.6 \mathrm{~V}$. The charge plateau is related to the oxidation from $\mathrm{S}^{2-}$ to $\mathrm{S}_{\mathrm{x}}{ }^{2-}$ and finally to produce $\mathrm{S}_{8}$ [48]. The first discharge plateau located at about $2.3 \mathrm{~V}$ represent the oxidation of elemental sulfur to long-chained polysulfides $\left(\mathrm{Li}_{2} \mathrm{~S}_{n}\right.$ for $\left.\mathrm{n} \geq 4\right)$ while the second plateau at $2.0 \mathrm{~V}$ is due to the decomposition of the long chained polysulfides to the insoluble products of $\mathrm{Li}_{2} \mathrm{~S}_{2}$ and $\mathrm{Li}_{2} \mathrm{~S}$ [49].

The cyclic voltammetry (CV) profiles with RPC/S-4 samples as composite cathode materials for $\mathrm{Li}-\mathrm{S}$ cells in the first three cycles are illustrated in Fig. 7a. There are two apparent reduction peaks at about 2.3 and $2.0 \mathrm{~V}$ which are due to the subsequent reduction of elemental sulfurto soluble lithium polysulfides $\left(\mathrm{Li}_{2} \mathrm{~S}_{n}, 4 \leq \mathrm{n} \leq 8\right)$ and finally, the conversion to insoluble $\mathrm{Li}_{2} \mathrm{~S}_{2}$ and $\mathrm{Li}_{2} \mathrm{~S}$, confirmed by the voltage profiles in Fig. $6 \mathrm{c}$. The broad oxidation peak located at $2.6 \mathrm{~V}$ is related to the the oxidation of $\mathrm{Li}_{2} \mathrm{~S}_{2}$ and $\mathrm{Li}_{2} \mathrm{~S}$ into longchained and soluble polysulfides. Furthermore, we can see that the CV profiles in the next cycles are overlapped and similar in shape. It shows that the reversibility the composite cathode materials has been enhanced during cycle tests.

Figure $7 \mathrm{~b}$ depicts the $\mathrm{CV}$ measurements of RPC/S-4 samples by varying the scan rate from 0.1 to $0.5 \mathrm{mV} \mathrm{s}^{-1}$. The redox anodic $\left(A_{1}\right)$ and cathodic $\left(C_{1}\right.$ and $\left.C_{2}\right)$ peak currents follow the linear relationship with square root of scan rates, as shown by the Randles Sevcik equation: 

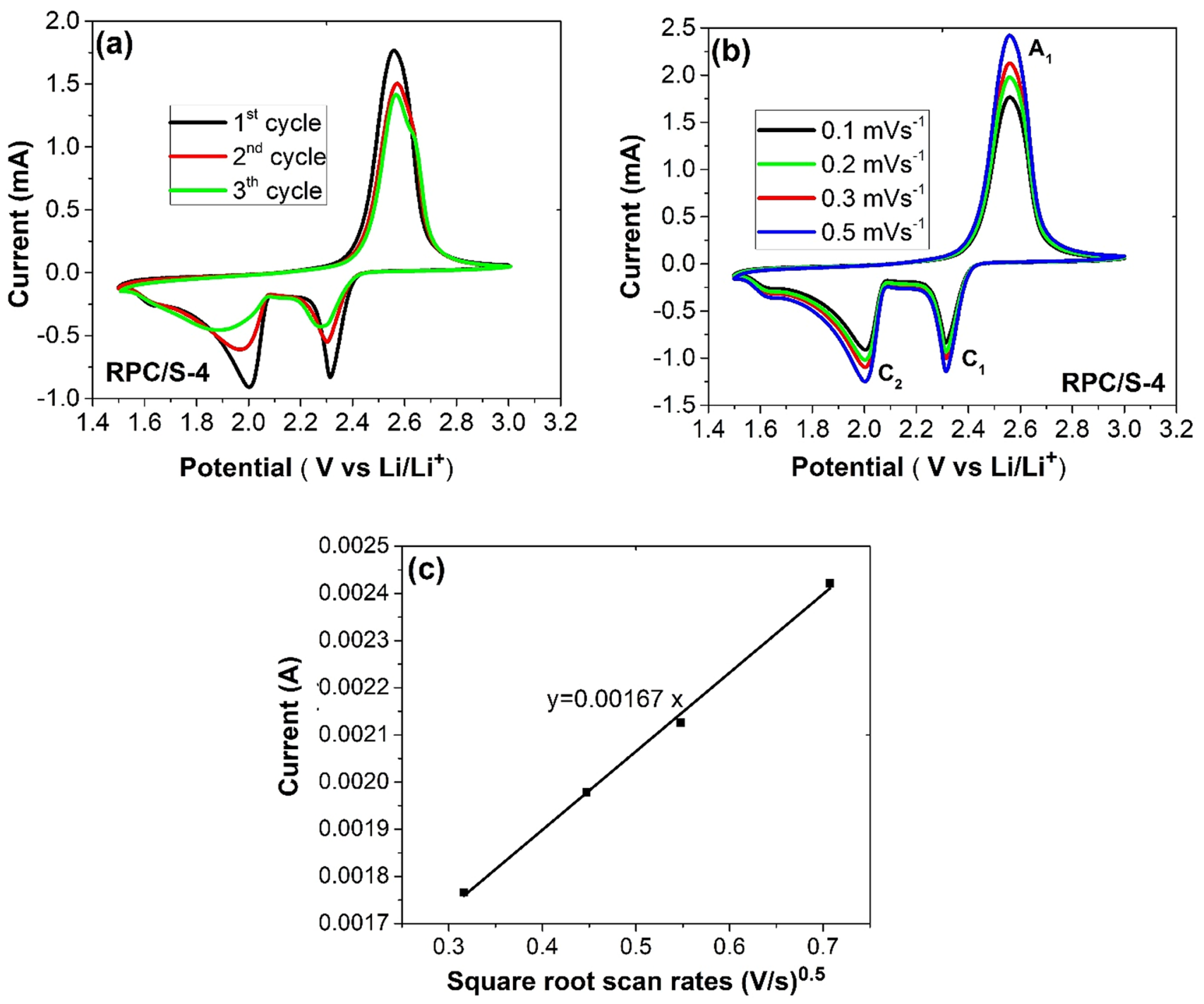

Fig. 7 a Cyclic Voltammetry (CV) profiles of RPC/S-4 in the first three cycles at scan rate of $0.1 \mathrm{mV} \mathrm{s}^{-1}$, b CV of RPC/S-4 in the first cycle measured at different scan rates, and $\mathbf{c}$ linear plotting of current vs square root scan rates

$I_{p}=2.69 \times 10^{5} n^{1.5} A D_{L i+}^{0.5} C V^{0.5}$

where, $I_{p}$ is the corresponding cathodic/anodic peaks current, $n$ is the numbers of electron transfer, $A$ is the active electrode area, $D_{L i+}$ is the lithium ions diffusion coefficient, $C$ is the concentration of lithium ions, and $v$ is the scan rate. The lithium-ion diffusion coefficient of RPC/S-4 can be estimated by using the linear regression, as shown in Fig. 7c. It is about $3.2 \times 10^{-10} \mathrm{~cm}^{2} \mathrm{~s}^{-1}$. This value is lower than those found in the literature such as graphene based composite $[47,50]$.
In order to study in detail about the electrochemical performance, the rate capability of all RPC/S electrodes were also conducted, as shown in Fig. 8. The three samples were measured with various $C$-rate varying from 0.2 to $2 \mathrm{C}\left(1 \mathrm{C}=1675 \mathrm{~mA} \mathrm{~g}^{-1}\right)$. The stable specific discharge capacities of RPC/S-4 composite at 0.2 C, 0.3 C, 0.4 C, 0.5 C, 1 C, 2 C and 3 C are $1100,875,750,625,500$ and 375 $\mathrm{mAh} \cdot \mathrm{g}^{-1}$, respectively. Furthermore, the discharge capacity of $1000 \mathrm{mAh} \cdot \mathrm{g}^{-1}$ can still be reached when the current density returned back to $0.2 \mathrm{C}$. It shows that the RPC/S-4 


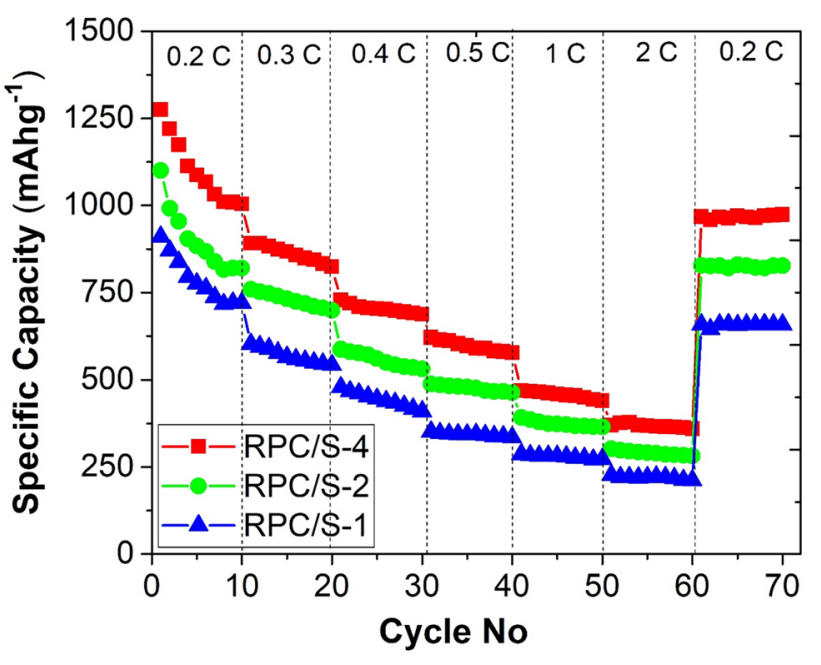

Fig. 8 Rate capabilities of RPC/S-1, RPC/S-2 and RPC/S-4 samples

composite has a the most stable and robust cycle performance among others. The main role of porous carbon with large pore volume is to contain more amount of active sulfur as well as to accommodate the volume expansion of sulfur during discharge process. In addition, the interconnected micro-mesoporous structures of carbons can provide diffusion channels for facile $\mathrm{Li}^{+}$diffusion. The electrochemical characteristics comparisons among biomass based carbon-sulfur composites are shown in Table 3.

\section{Conclusions}

In summary, waste rambutan peels were employed as carbons precursors to derive porous carbon materials to encapsulate sulfur cathodes for $\mathrm{Li}-\mathrm{S}$ batteries. Due to the high surface area and large pore volume, the RPC/S electrodes demonstrated superior rate capacity and stable cycle performance. The large pore volume enables the porous carbons to load high content of sulfur. As a results, the best RPC/S cathodes with sulfur loading of $68.2 \mathrm{wt} \%$ possesses a high initial specific capacity of about 1275 $\mathrm{mAh} \mathrm{g}^{-1}$ at $0.2 \mathrm{C}$ rate with high Coulombic efficiency above $97 \%$ and a high capacity of $936 \mathrm{mAh} \mathrm{g}^{-1}$ after 200 cycles. The $\mathrm{Li}^{+}$diffusion coefficient in the RPC/S composites has been estimated as $3.2 \times 10^{-10} \mathrm{~cm}^{2} \mathrm{~s}^{-1}$, implying a fast transport rate of Li.
Table 3 Comparison of electrochemical performances of various biomass based porous carbons as composite cathodes for LiS Battery

\begin{tabular}{llllll}
\hline No & Biomass Precursors & $\begin{array}{l}\text { Final Capacity } \\
\left(\mathrm{mAh} \mathrm{g}^{-1}\right)\end{array}$ & Cycle No & C-Rate & $\begin{array}{l}\text { Sulfur } \\
\text { Content } \\
\text { (wt\%) }\end{array}$ \\
\hline 1 & Avocado shells [25] & 529.85 & 100 & $0.1 \mathrm{C}$ & 55 \\
2 & Snake-skin fruit peel [26] & 598 & 100 & $0.1 \mathrm{C}$ & 63 \\
3 & Hickory shell [27] & 607.7 & 300 & $0.1 \mathrm{C}$ & 55 \\
4 & Rapeseed meal [28] & 512 & 200 & $0.1 \mathrm{C}$ & 71.35 \\
5 & Moss [29] & 708 & 100 & $0.1 \mathrm{C}$ & 58 \\
6 & Dandelion [30] & 800 & 500 & $0.5 \mathrm{C}$ & 58 \\
7 & Banana peel [31] & 615 & 500 & $0.5 \mathrm{C}$ & 65 \\
8 & Fiber of fern [32] & 753 & 100 & $0.2 \mathrm{C}$ & 66.4 \\
9 & Wheat straw [33] & 454.7 & 500 & $1 \mathrm{C}$ & 63.6 \\
10 & Mangosteen peel [34] & 599.6 & 100 & $0.5 \mathrm{C}$ & 65 \\
11 & Xanthoceras sorbifolia husks [35] & 442.4 & 500 & $1 \mathrm{C}$ & 52 \\
12 & Goat hair [36] & 489 & 300 & $0.2 \mathrm{C}$ & 54.33 \\
13 & Rice husks [37] & 720 & 200 & $0.2 \mathrm{C}$ & 56 \\
14 & Pistachio shell [38] & 570 & 300 & $0.1 \mathrm{C}$ & 70 \\
15 & Almond shell [39] & 760 & 100 & $0.1 \mathrm{C}$ & 60 \\
16 & Waste tea [17] & 627 & 100 & $0.05 \mathrm{C}$ & 59.5 \\
17 & This work & 936 & 200 & $0.2 \mathrm{C}$ & 68.2 \\
\hline
\end{tabular}


Acknowledgement This study is supported by the "Direktorat Riset dan Pengabdian Masyarakat Kementerian Riset dan Teknologi/Badan Riset dan Inovasi Nasional" of Ministry of Research and Technology of Republic Indonesia (KEMENRISTEK/BRIN) through "Hibah Penelitian Dasar Sentralisasi Nasional" (Contract No: 020/SP2H/LT-AMAND/ LL4/2020) in 2020) and Korea Institute of Science and Technology (KIST) Institutional Program.

\section{Declarations}

Conflict of interest The authors declare that they have no conflict of interest.

Open Access This article is licensed under a Creative Commons Attribution 4.0 International License, which permits use, sharing, adaptation, distribution and reproduction in any medium or format, as long as you give appropriate credit to the original author(s) and the source, provide a link to the Creative Commons licence, and indicate if changes were made. The images or other third party material in this article are included in the article's Creative Commons licence, unless indicated otherwise in a credit line to the material. If material is not included in the article's Creative Commons licence and your intended use is not permitted by statutory regulation or exceeds the permitted use, you will need to obtain permission directly from the copyright holder. To view a copy of this licence, visit http://creativecommons. org/licenses/by/4.0/.

\section{References}

1. Deng D (2015) Li-ion batteries: basics, progress, and challenges. Energy Sci Eng 3:385-418. https://doi.org/10.1002/ese3.95

2. Kaiser MR, Han Z, Liang J et al (2019) Lithium sulfide-based cathode for lithium-ion/sulfur battery: recent progress and challenges. Energy Storage Mater 19:1-15. https://doi.org/10. 1016/j.ensm.2019.04.001

3. He J, Manthiram A (2019) A review on the status and challenges of electrocatalysts in lithium-sulfur batteries. Energy Storage Mater 20:55-70. https://doi.org/10.1016/j.ensm.2019.04.038

4. Kang W, Deng N, Ju J et al (2016) A review of recent developments in rechargeable lithium-sulfur batteries. Nanoscale 8:16541-16588. https://doi.org/10.1039/C6NR04923K

5. Nara H, Tsuda S, Osaka T (2017) Techniques for realizing practical application of sulfur cathodes in future Li-ion batteries. J Solid State Electrochem 21:1925-1937. https://doi.org/10.1007/ s10008-017-3629-9

6. Fotouhi A, Auger D, O'Neill L et al (2017) Lithium-sulfur battery technology readiness and applications-a review. Energies 10:1937. https://doi.org/10.3390/en10121937

7. Zeng LC, Li WH, Jiang Y, Yu Y (2017) Recent progress in Li-S and Li-Se batteries. Rare Met 36:339-364. https://doi.org/10.1007/ s12598-017-0891-z

8. Ma L, Hendrickson KE, Wei S, Archer LA (2015) Nanomaterials: science and applications in the lithium-sulfur battery. Nano Today 10:315-338. https://doi.org/10.1016/j.nantod.2015.04. 011

9. Fu C, Guo J (2016) Challenges and current development of sulfur cathode in lithium-sulfur battery. Curr Opin Chem Eng 13:53-62. https://doi.org/10.1016/j.coche.2016.08.004

10. Borchardt L, Althues H, Kaskel S (2017) Carbon nano-composites for lithium-sulfur batteries. Curr Opin Green Sustain Chem 4:64-71. https://doi.org/10.1016/j.cogsc.2017.02.008

11. Bandosz TJ, Ren T (2017) Porous carbon modified with sulfur in energy related applications. Carbon 118:561-577
12. Li Z, Huang Y, Yuan L (2015) Status and prospects in sulfur - carbon composites as cathode materials for rechargeable lithium - sulfur batteries. Carbon N Y 92:41-63. https://doi. org/10.1016/j.carbon.2015.03.008

13. Liang J, Sun ZH, Li F, Cheng HM (2016) Carbon materials for Li-S batteries: functional evolution and performance improvement. Energy Storage Mater 2:76-106. https://doi.org/10. 1016/j.ensm.2015.09.007

14. Wang $M, X i a X$, Zhong $Y$ et al (2019) Porous carbon hosts for lithium-sulfur batteries. Chem - A Eur J 25:3710-3725. https:// doi.org/10.1002/chem.201803153

15. Le SJ, Tang C, Huang JQ et al (2018) Effective exposure of nitrogen heteroatoms in 3D porous graphene framework for oxygen reduction reaction and lithium-sulfur batteries. J Energy Chem 27:167-175. https://doi.org/10.1016/j.jechem.2017.09. 014

16. Zhao Y, Ren J, Tan T et al (2017) Biomass waste inspired highly porous carbon for high performance lithium/sulfur batteries. Nanomaterials 7:260. https://doi.org/10.3390/nano7090260

17. Półrolniczak P, Nowicki P, Wasiński K et al (2016) Biomass-derived hierarchical carbon as sulfur cathode stabilizing agent for lithium-sulfur batteries. Solid State lon 297:59-63. https://doi.org/ 10.1016/j.ssi.2016.10.012

18. Imtiaz S, Zhang J, Zafar ZA et al (2016) Biomass-derived nanostructured porous carbons for lithium-sulfur batteries. Sci China Mater 59:389-407. https://doi.org/10.1007/s40843-016-5047-8

19. Kaiser MR, Ma Z, Wang $X$ et al (2017) Reverse microemulsion synthesis of sulfur/graphene composite for lithium/sulfur batteries. ACS Nano 11:9048-9056. https://doi.org/10.1021/acsna no.7b03591

20. Rejaul Kaiser M, Wang J, Liang X et al (2015) A systematic approach to high and stable discharge capacity for scaling up the lithium-sulfur battery. J Power Sour 279:231-237. https:// doi.org/10.1016/j.jpowsour.2014.12.098

21. Liang X, Kaiser MR, Konstantinov K et al (2016) Ternary porous sulfur/dual-carbon architectures for lithium/sulfur batteries obtained continuously and on a large scale via an industryoriented spray-pyrolysis/sublimation method. ACS Appl Mater Interf 8:25251-25260. https://doi.org/10.1021/acsami.6b07012

22. Cengiz EC, Demir-Cakan R (2020) TiO2 embedded hydrothermally synthesized carbon composite as interlayer for lithiumsulfur batteries. J Solid State Electrochem 24:2469-2478. https:// doi.org/10.1007/s10008-020-04785-x

23. Kaiser MR, Han Z, Wang J (2019) Electro-polymerized polypyrrole film for fabrication of flexible and slurry-free polypyrrole-sulfurpolypyrrole sandwich electrode for the lithium-sulfur battery. J Power Sour 437:226925. https://doi.org/10.1016/j.jpowsour. 2019.226925

24. Kaiser MR, Liang X, Konstantinov K et al (2015) A facile synthesis of high-surface-area sulfur-carbon composites for $\mathrm{Li} / \mathrm{S}$ batteries. Chem - A Eur J 21:10061-10069. https://doi.org/10.1002/chem. 201500429

25. Fawaz W, Mosavati N, Abdelhamid E, Simon Ng KY (2019) Synthesis of activated carbons derived from avocado shells as cathode materials for lithium-sulfur batteries. SN Appl Sci 1:1-10. https://doi.org/10.1007/s42452-019-0300-3

26. Arie AA, Kristianto H, Cengiz EC, Demir-Cakan R (2019) Activated porous carbons originated from the Indonesian snake skin fruit peel as cathode components for lithium sulfur battery. lonics (Kiel) 25:2121-2129. https://doi.org/10.1007/s11581-018-2712-2

27. Leng S, Chen C, Liu J et al (2019) Optimized sulfur-loading in nitrogen-doped porous carbon for high-capacity cathode of lithium-sulfur batteries. Appl Surf Sci 487:784-792. https://doi. org/10.1016/j.apsusc.2019.05.206

28. Xia L, Song Z, Zhou L et al (2019) Nitrogen and oxygen dualdoped hierarchical porous carbon derived from rapeseed meal 
for high performance lithium-sulfur batteries. J Solid State Chem 270:500-508. https://doi.org/10.1016/j.jssc.2018.12.031

29. Lei W, Liu H, Xiao J et al (2019) Moss-derived mesoporous carbon as bi-functional electrode materials for lithium-sulfur batteries and supercapacitors. Nanomaterials 9:84. https://doi.org/10. 3390/nano9010084

30. Ren J, Zhou Y, Wu H et al (2019) Dandelion derived nitrogendoped hollow carbon host for encapsulating sulfur in lithium sulfur battery. ACS Sustain Chem Eng 121:3042-3051. https:// doi.org/10.1021/acssuschemeng.8b04648

31. Xue M, Lu W, Chen C et al (2019) Optimized synthesis of banana peel derived porous carbon and its application in lithium sulfur batteries. Mater Res Bull 112:269-280. https://doi.org/10.1016/j. materresbull.2018.12.035

32. You X, Liu L, Zhang M et al (2018) Novel biomass derived hierarchical porous carbon for lithium sulfur batteries. Mater Lett 217:167-170. https://doi.org/10.1016/j.matlet.2018.01.096

33. Chen F, Ma L, Ren J et al (2018) Wheat straw-derived N-, O-, and S-tri-doped porous carbon with ultrahigh specific surface area for lithium-sulfur batteries. Materials (Basel) 11:1-15. https://doi. org/10.3390/ma11060989

34. Xue M, Chen C, Tan Y et al (2018) Mangosteen peel-derived porous carbon: synthesis and its application in the sulfur cathode for lithium sulfur battery. J Mater Sci 53:11062-11077. https://doi.org/10.1007/s10853-018-2370-9

35. Zhou X, Lu X, Zhang Z et al (2018) Xanthoceras sorbifolia husksderived porous carbon for sodium-ion and lithium-sulfur batteries. Diam Relat Mater 85:104-111. https://doi.org/10.1016/j. diamond.2018.04.007

36. Ren J, Zhou Y, Wu H et al (2019) Sulfur-encapsulated in heteroatom-doped hierarchical porous carbon derived from goat hair for high performance lithium-sulfur batteries. J Energy Chem 121:121-131. https://doi.org/10.1016/j.jechem.2018.01.015

37. Rybarczyk MK, Peng HJ, Tang C et al (2016) Porous carbon derived from rice husks as sustainable bioresources: Insights into the role of micro-/mesoporous hierarchy in hosting active species for lithium-sulphur batteries. Green Chem 18:51695179. https://doi.org/10.1039/c6gc00612d

38. Benítez A, Morales J, Caballero Á (2020) Pistachio shell-derived carbon activated with phosphoric acid: a more efficient procedure to improve the performance of li-s batteries. Nanomaterials. https://doi.org/10.3390/nano10050840

39. Benítez A, González-Tejero M, Caballero Á, Morales J (2018) Almond shell as a microporous carbon source for sustainable cathodes in lithium-sulfur batteries. Materials (Basel). https:// doi.org/10.3390/ma11081428
40. Arie AA, Kristianto H, Cengiz EC, Demir-Cakan R (2020) Waste tea-based porous carbon-sulfur composite cathodes for lithium-sulfur battery. Ion 26:201-212. https://doi.org/10.1007/ s11581-019-03196-x

41. Wang J, Nie P, Ding B et al (2017) Biomass derived carbon for energy storage devices. J Mater Chem A 5:2411-2428. https:// doi.org/10.1039/C6TA08742F

42. Mahmood K, Kamilah H, Alias AK, Ariffin F (2018) Nutritional and therapeutic potentials of rambutan fruit (Nephelium lappaceum L.) and the by-products: a review. J Food Meas Charact 12:1556-1571. https://doi.org/10.1007/s11694-018-9771-y

43. Kumar M, Olajire Oyedun A, Kumar A (2018) A review on the current status of various hydrothermal technologies on biomass feedstock. Renew Sustain Energy Rev 81:1742-1770. https://doi. org/10.1016/j.rser.2017.05.270

44. Oh C, Yoon N, Choi J et al (2017) Enhanced Li-S battery performance based on solution-impregnation-assisted sulfur/ mesoporous carbon cathodes and a carbon-coated separator. J Mater Chem A 5:5750-5760. https://doi.org/10.1039/c7ta01161j

45. Zhang B, Qin X, Li GR, Gao XP (2010) Enhancement of long stability of sulfur cathode by encapsulating sulfur into micropores of carbon spheres. Energy Environ Sci 3:1531-1537. https://doi. org/10.1039/c002639e

46. Elazari R, Salitra G, Garsuch A et al (2011) Sulfur-impregnated activated carbon fiber cloth as a binder-free cathode for rechargeable Li-S batteries. Adv Mater 23:5641-5644. https:// doi.org/10.1002/adma.201103274

47. Kim H, Lim HD, Kim J, Kang K (2014) Graphene for advanced Li/S and Li/air batteries. J Mater Chem A 2:33-47. https://doi.org/10. 1039/c3ta12522j

48. You X, long, Liu L jun, Zhang M yuan, et al (2018) Novel biomass derived hierarchical porous carbon for lithium sulfur batteries. Mater Lett 217:167-170. https://doi.org/10.1016/j.matlet.2018. 01.096

49. Zhao Y, Zhang X, He Y et al (2017) Biomass derived nitrogendoped highly porous carbon material with a hierarchical porous structure for high-performance lithium/sulfur batteries. Materials (Basel). https://doi.org/10.3390/ma10101158

50. Benítez A, Caballero A, Morales J et al (2019) Physical activation of graphene: an effective, simple and clean procedure for obtaining microporous graphene for high-performance Li/S batteries. Nano Res 12:759-766. https://doi.org/10.1007/ s12274-019-2282-2

Publisher's Note Springer Nature remains neutral with regard to jurisdictional claims in published maps and institutional affiliations. 